are perhaps more tables of economic statistics than are really necessary. Further, the book ends somewhat abruptly and unexpectedly in a cranberry bog in Martha's Vineyard, Massachusetts. It lacks a concluding statement.

This is unfortunate. For it is elear to one who has visited nearly all the areas described by the author that his descriptions and bio-geographical analyses are accurate and perceptive. It would have been helpful to know what ecological and economic principles suggested themselves to his mind as a result of this most interesting and informative survey of American agriculture.

A. N. DUCKham

\section{SCIENTIFIC APPLICATIONS OF SCIENCE}

\section{Operational Research in Practice}

Report of a NATO Conference. Edited by Max Davies and Michel Verhulst. Pp. ix +201 . (London and New York: Pergamon Press, 1958. Published for and on behalf of Advisory Group of Aeronautical Research and Development, North Atlantic Treaty Organization.) 84s. net.

IN setting up what was to become the first sodesignated Operational Research Section in Fighter Command, Watson-Watt was the first to achieve the most thorough application of science itself. Radar was entirely new, and the momentum of its application carried the scientist into the heart of tactics and strategy. So it was that his formulation of the duties of operational research sections remains valid even until to-day, as Sír Solly Zuckerman emphasizes in his introduction to the report of this North Atlantic Treaty Organization conference.

But how has operational research fared since then ? It is still firmly embedded in military practice, despite the shift of emphasis from current operations to future ones, the evaluation of exercises and the development of war games. Here, due to the speed of innovation, there is little scope for hardening into conventional wisdom (to borrow from Prof. Galbraith) in regard to the conduct of military operations, the conventional wisdom of war itself being the accepted framework. But some important applications of operational research were in fields where past procedures, at one time relevant, provided the precedent. Within the Armed Services the civilian scientists were able to make a break-through, perhaps hecause they were unaffected by conventional wisdom.

Immediately after the Second World War the scope for scientists seemed as wide as human activity itself. The prevailing mood is now more sober, as shown by thoughtful contributions on decision-making and war games, both in civil and military situations, with the need for a theoretical rationale. Logistic and transport problems are shown to have the same basic structure, but let the user beware of an uncritical borrowing of technique, for seemingly slight differences might turn out to be important.

There is, however, one extremely important difference. In civil applications (as quoted) a 1 per cent increase in efficiency (as measured by gross profits) leading to an increase of 5 per cent in distributed profit is an achievement that firms are willing to pay for-whether or not it represents a good national use of searce man-power. The reaction of a professional soldier is that "in a military context such improvements were seldom ever meaningful or worthwhile". He continues: "The application of operational research principles to operational research was highly desirable, but all too rare". I know of no university where an expert in "tensions in industry" from the sociology department has been invited to report on the tensions within the university.

CeCIL Gordon

\section{BACTERIAL POPULATION STUDIES IN THE CHEMOSTAT}

\section{The Dynamics of Bacterial Populations maintained in the Chemostat.}

By Hermann Moser. Pp. iv +136 . (Publication No. 614.) (Washington, D.C. : Carnegie Institution of Washington, 1958.) Paper, 1.15 dollars; Cloth, 1.40 dollars.

THE study of the mechanisms by which bacterial populations become better fitted to a given environment is of considerable fundamental importance. Of the various methods available for the study of such problems those using a continuous culture apparatus are especially valuable since the cells can be maintained in a state of active growth under defined conditions. In the simplest kind of continuous-culture apparatus the nutrient medium in the culture tube is automatically renewed and immediately a portion of the bacterial suspension is removed, thus maintaining (after a certain time of operation) a steady state. The chemostat superimposes another form of control on the growth, by keeping the concentration of one of the constituents of the growth medium at a sufficiently low level so that the bacterial population grows at a reduced rate which is a direct function of this concentration and is independent of all other nutrient factors.

Although the fundamental theory of growth in the chemostat has been presented by other workers, whose contribution the author generously acknowledges, the genetic theory of populations, it is elaimed, has not been presented in a satisfactory way. This task the author has set himself and he proceeds to predict and discuss "the various patterns in which mutants of different kinds may accumulate in a continuously growing population and the ways in which genetic equilibria are attained in such populations". He maintains that "since we are dealing with non-sexual bacteria, the sole factors influencing the frequency of mutants in the population to be considered are the capacity to mutate, and selection". He considers both specific and periodic selection.

On the basis of these assumptions the author proceeds to set up a population model and to examine in considerable mathematical detail the numerous aspects of the problem. The mathematical treatment is the most comprehensive the reviewer has seen and it is recommended to anyone interested in this subject. However, the reviewer feels that it is a pity that the fundamental assumptions of mutation followed by selection were not more rigorously confirmed. It would have provided a better balance if the complementary mechanism of adaptation by nongenetic means had been considered (if only to be rejected), especially since the theory of periodic selection has been challenged for at least one example.

The book is well written and is produced to the usual high standard of the publications of the Carnegie Institution of Washington.

A. C. R. Dean 